University of Nebraska - Lincoln

DigitalCommons@University of Nebraska - Lincoln

July 2003

\title{
Effects of a Multicomponent Intervention on Motivation and Sun Protection Behaviors Among Midwestern Beachgoers
}

\author{
Sherry Pagota \\ University of Illinois at Chicago and Edward Hines, Jr. Veterans Affairs Hospital \\ Dennis E. McChargue \\ University of Nebraska-Lincoln, dmcchargue2@unl.edu \\ R. Wayne Fuqua \\ Western Michigan University
}

Follow this and additional works at: https://digitalcommons.unl.edu/psychfacpub

Part of the Psychiatry and Psychology Commons

\begin{abstract}
Pagota, Sherry; McChargue, Dennis E.; and Fuqua, R. Wayne, "Effects of a Multicomponent Intervention on Motivation and Sun Protection Behaviors Among Midwestern Beachgoers" (2003). Faculty Publications, Department of Psychology. 261.

https://digitalcommons.unl.edu/psychfacpub/261
\end{abstract}

This Article is brought to you for free and open access by the Psychology, Department of at DigitalCommons@University of Nebraska - Lincoln. It has been accepted for inclusion in Faculty Publications, Department of Psychology by an authorized administrator of DigitalCommons@University of Nebraska - Lincoln. 


\title{
Effects of a Multicomponent Intervention on Motivation and Sun Protection Behaviors Among Midwestern Beachgoers
}

\author{
Sherry Pagoto and Dennis McChargue \\ University of Illinois at Chicago and Edward Hines, Jr. \\ Veterans Affairs Hospital
}

\author{
R. Wayne Fuqua \\ Western Michigan University
}

\begin{abstract}
Skin cancer is the most prevalent of all cancers in the United States. Although avoiding sun exposure and using sun protection reduces skin cancer risk, rates of such behaviors are moderate at best. The present study examined the impact of a multicomponent intervention that aimed to increase the saliency of skin cancer risk while promoting the use of sun protection. Midwestern beachgoers $(n=100)$ participated in an intervention or questionnaire-only control group. Sun protection, stage of change, and sun exposure were measured at baseline and 2-month follow-up. The intervention group significantly improved in sun protection use and stage of change, but not sun exposure, compared with the control group. Personalizing the risks of unprotected sun exposure combined with providing education about sun protection facilitated healthy changes in behavior and motivation.
\end{abstract}

Key words: prevention, skin cancer, multicomponent intervention, sun protection, sun exposure

Incidence of skin cancer in the United States is nearly equivalent to that of all other cancers combined (D. L. Miller \& Weinstock, 1994). Although sun protection behavior (e.g., sunscreen use) can reduce skin cancer risk (Center for Disease Control, 1995), U.S. adult Caucasians report low to moderate rates $(11 \%-53 \%)$ of sun protection behavior and moderate to high rates of sun exposure (Newman, Agro, Woodruff, \& Mayer, 1996; Weinstock, Rossi, Redding, Maddock \& Cottrill, 2000). The ease with which people can protect themselves from the sun contrasts with reports of marginal rates of sun protection use. Health promotion interventions that address barriers to sun protection use are needed to facilitate sun protection and sun avoidance.

The transtheoretical stages of change model identifies five stages of behavior change ranging from the precontemplation stage, at which the individual has not yet identified the need to change behavior, to the maintenance stage, at which the individual engages in long-lasting behavior change (Prochaska \& DiClemente, 1983). Systematic patterns have been identified in sun protection behavior such that the disadvantages of changing be-

Sherry Pagoto and Dennis McChargue, Department of Psychology, University of Illinois at Chicago, and Edward Hines, Jr. Veterans Affairs Hospital, Hines, Illinois; R. Wayne Fuqua, Department of Psychology, Western Michigan University.

This research was supported by Blue Cross Blue Shield Foundation of Michigan Award 311.SAP.98 to Sherry Pagoto, as well as National Institutes of Health Grant K08DA00467-01 to Dennis McChargue.

We thank Canfield Scientific, Inc., for providing photographic equipment and supplies, including the Reflec UV Instant Camera System. We also thank Paul Jasper, C. Richard Spates, Scott Kollins, William Fenn, and Maria Margarita Trejo for their assistance with this project.

Correspondence concerning this article should be addressed to Sherry Pagoto, Department of Psychology (M/C 285), University of Illinois at Chicago, 1009 Behavioral Sciences Building, 1007 W. Harrison Street, Chicago, Illinois 60607. E-mail: spagoto@uic.edu havior outweigh the advantages in earlier stages of change and vice versa in later stages of change (Prochaska et al., 1994). For example, people who commonly go without sun protection are less sensitive to harmful effects of the sun (e.g., low burn potential), perceive sun exposure as enhancing physical appearance, and often do not perceive themselves to be at risk for skin cancer (Balanda, Stanton, Lowe, \& Purdue, 1999; Wichstrøm, 1994). In contrast, people who experience the negative consequences of unprotected sun exposure, such as frequent sunburn or skin cancer, are the most consistent users of sun protection (Broadstock, Borland, \& Hill, 1996; Robinson \& Rademaker, 1995).

For many, beliefs about the benefits of sun exposure (e.g., desired suntan) markedly outweigh beliefs about sun-related risks (Jackson \& Aiken, 2000; Jones, Harris, \& Chrispin, 2000). As a result, health promotion efforts have been designed to bolster rates of sun protection behavior by emphasizing the benefits of protection and reduced sun exposure via health education (Detweiler Bedell, Salovey, Pronin, \& Rothman, 1999; Dixon, Borland, \& Hill, 1999), message framing (Rothman, Salovey, Antone, Keough, \& Martin, 1993), and media campaigns (Koh, Geller, Miller, Grossbart, \& Lew, 1996; Koh, Geller, Miller, \& Lew, 1995). Such interventions enhance knowledge but, in most cases, fail to result in behavior change (e.g., Dixon et al., 1999; Lowe et al., 2000).

Alternatively, health promotion interventions involving multiple components have been shown to increase sun protection behavior. For example, a publicity campaign combined with a behavioral intervention produced significantly fewer sunburns and increased sunscreen use among children across a 3-year period (D. R. Miller, Geller, Wood, Lew, \& Koh, 1999). Also, a multicomponent behavioral intervention using peer modeling, feedback, prompts, and commitment contracting increased sun protection behaviors at public pools by $22 \%-38 \%$ (Lombard, Neubauer, Canfield, \& Winett, 1991). Moreover, interventions that increase the personal relevance or salience of skin cancer risk via public melanoma 
screenings (Brandberg et al., 1996), sun protection education with melanoma patients (Robinson \& Rademaker, 1995), or the use of ultraviolet (UV) photography that illuminates skin damage (Weinstock \& Rossi, 1998; Weinstock, Rossi, Redding, \& Maddock, 1998) have shown much potential to enhance sun protection behavior.

The present study tested the efficacy of a multicomponent intervention designed to provide education and enhance the personal relevance of sun-related risks. The intervention is unique in that it was delivered in a setting where high-risk behavior regularly occurs (i.e., the beach), and the impact of the intervention on both behavior and motivation was assessed. Many studies have examined changes in attitudes and knowledge, but not behavior (e.g., Hillhouse \& Turrisi, 2002; Katz \& Jernigan, 1991), and only one, to our knowledge, assessed impact on motivation (Rossi, Blais, \& Weinstock, 1994). Measures of motivation may be more sensitive to the process of change than even direct measures of behavior (Rossi, Blais, Redding, \& Weinstock, 1995). Our specific aim was to test the hypothesis that shifts across motivational stages of change, increases in sun protection behavior, and decreases in sun exposure would be evident in the intervention group as compared with a questionnaire-only control group.

\section{Method}

\section{Participants}

Midwestern beachgoers $(N=257)$ participated in this study, which was in full compliance with internal review board guidelines. Participants were at least 18 years old and English speaking. Overall, 100 participants (63\% female; 53 intervention, 47 control) provided complete data. Table 1 illustrates group comparisons on demographic and dependent variables. Individuals who provided incomplete data were classified as noncompleters and were not included in the analyses. No differences in age, gender, educational status, ethnicity, sun protection behavior, sun exposure, or stage were found between completers and noncompleters. Also, completers and noncompleters were equally as likely to be in the intervention and control groups.

\section{Materials}

Sun stage of change. A staging algorithm developed by Rossi et al. (1994) was used to classify participants into one of the five stages of change (i.e., precontemplation, contemplation, preparation, action, and maintenance). The staging algorithm comprises two categories of four questions each. Category 1 assesses the use of and intentions to use general sun protection (i.e., using sunscreen, using protective clothing, limiting sun exposure). Category 2 assesses the use of and intentions to use sunscreen with a sun protection factor (SPF) of 15 . The action-maintenance stage of this scale correlates with variables linked to sun protection behavior (e.g., family history of skin cancer; Weinstock et al., 2000).

Sun protection behavior. Consistent with Pratt and Borland (1994), sun protection behavior was assessed using a composite score of items that included (a) frequency of sunscreen use (SPF 15 or higher), (b) frequency of protective clothing use during sun exposure, and (c) the number of body parts protected from sun. Items (a) and (b) were rated on a 4-point Likert-type scale, which ranged from very seldom to always. Item (c) was assigned a rating that ranged from 0 (no body parts covered) to 3 (all body parts covered). A composite score was created because adequate sun protection requires the use of sunscreen or protective clothing on all exposed body parts. Composite scores were calculated by adding the highest score from Items (a) and (b) to Item (c). Items were moderately
Table 1

Group Comparisons at Baseline

\begin{tabular}{|c|c|c|c|c|c|c|}
\hline \multirow[b]{2}{*}{ Variable } & \multicolumn{3}{|c|}{$\begin{array}{l}\text { Intervention } \\
(n=53)\end{array}$} & \multicolumn{3}{|c|}{$\begin{array}{c}\text { Control } \\
(n=47)\end{array}$} \\
\hline & $\%$ & $M$ & $S D$ & $\%$ & $M$ & $S D$ \\
\hline Age & & 27.96 & 6.17 & & $24.49 * *$ & 3.21 \\
\hline Sun protection & & 5.52 & 1.84 & & 5.55 & 1.85 \\
\hline Sun exposure & & 14.90 & 16.90 & & $7.53 * *$ & 7.01 \\
\hline \multicolumn{7}{|l|}{ Gender } \\
\hline Male & 45 & & & $25^{*}$ & & \\
\hline Female & 55 & & & 75 & & \\
\hline \multicolumn{7}{|l|}{ Education } \\
\hline Less than high school & 0 & & & 0 & & \\
\hline High school & 17 & & & 15 & & \\
\hline College degree & 83 & & & 83 & & \\
\hline Unknown & 0 & & & 2 & & \\
\hline \multicolumn{7}{|l|}{ Skin type } \\
\hline I & 11 & & & 9 & & \\
\hline II & 28 & & & 15 & & \\
\hline III & 36 & & & 49 & & \\
\hline IV & 25 & & & 27 & & \\
\hline \multicolumn{7}{|l|}{ Stage of change } \\
\hline Precontemplation & 34 & & & 53 & & \\
\hline Contemplation & 0 & & & 2 & & \\
\hline Preparation & 39 & & & 23 & & \\
\hline Action & 8 & & & 11 & & \\
\hline Maintenance & 18 & & & 11 & & \\
\hline
\end{tabular}

Note. Detailed descriptions of the skin type categories are as follows: $\mathrm{I}=$ A painful burn the next day after $1 \mathrm{hr}$ of unprotected sun exposure; II = A painful burn the next day and a light tan 1 week later; III = A slightly tender burn the next day and a moderate tan 1 week later; IV = No burn the next day and a moderate $\tan 1$ week later.

$* p<.05$. ** $p<.01$.

related $(r=.20-.61, p<.05)$, and alpha was .63. Composite scores ranged from 1 to 7 with higher scores indicating increasing degree of sun protection.

Sun exposure. Sun exposure was evaluated by having participants estimate both the average number of days per week and the average number of hours per week they spent (a) sunbathing and (b) engaging in outdoor activities over the past 2 months (Wichstrøm, 1994). Composite scores were calculated by summing the number of hours per week sunbathing and engaging in outdoor recreational-occupational activities. Items were moderately related $(r=.38, p<.01)$, and alpha was .47 .

\section{Intervention}

The intervention included six components. First, participants were assessed for skin sensitivity to solar radiation and were provided sun protection recommendations consistent with their sensitivity level (Weinstock, 1992). Second, participants were provided with the American Cancer Society's (1999) pamphlet of safe sun recommendations. Third, sun damage was assessed via UV photos taken with the Reflec UV Instant Camera System (Canfield Imaging Systems; Fairfield, NJ). Facial photographs illuminate skin photodamage, a precursor to many skin cancers (Nicol \& Fenske, 1993). Participants' photos were compared to three standard photos that reflected varying degrees of skin damage. Fourth, commitment cards were signed by participants and cosigned by a friend. Participants were asked to post the card (and their photo) in a conspicuous place in their home as a reminder and prompt to use sun protection. Fifth, participants were offered a selection of free sunscreens and instructed on proper application of sunscreen. Last, research assistants modeled proper sun 
protection by repeatedly applying sunscreens and wearing protective clothing, hats, and sunglasses.

\section{Procedure}

Data were collected on the lakefront of a large Midwestern city during peak UV hours in the summer of 2000. Mean temperature across all days of data collection was $83{ }^{\circ} \mathrm{F}$, and cloud cover was minimal. Informed consent was received from interested beachgoers prior to study enrollment. To prevent contamination of the control group, we collected intervention and control group data simultaneously in locations separated by 1 mile (about $1.6 \mathrm{~km}$ ). Locations for control and intervention group data collection were both public access, sand-covered beach areas populated by predominantly Caucasian beachgoers of all ages.

Baseline. Participants completed three brief questionnaires about sun exposure, sun protection behavior, and stages of change. Intervention group participants then experienced the intervention as described above. All participants were informed that completing follow-up questionnaires would qualify them for a $\$ 100$ lottery and up to 150 people could be eligible for the lottery.

Two-month follow-up. Follow-up data about stage of change, sun protection behavior, and sun exposure were collected at 2 months. The follow-up data were collected during the latter months of summer, whereas baseline data were collected midsummer. Follow-up data collection was conducted by telephone, mail, and/or e-mail. E-mail resulted in the highest response rate $(56 \%)$, followed by mail $(52 \%)$, and phone $(7 \%)$. Each participant was contacted three times separated by 1 week.

\section{Results}

Two analyses of covariance (ANCOVAs) were used to examine group differences on sun protection and sun exposure with baseline values, age, and gender entered as covariates. We hypothesized that, after baseline group differences were controlled for, the intervention group would report significantly more sun protection behavior and less sun exposure than the control group at follow-up.

The ANCOVA for sun protection was significant, $F(5$, $96)=7.15, p<.01$. When baseline rates of sun protection and sun exposure were held constant, reports of sun protection use in the intervention group $(M=6.44)$ were significantly greater than in the control group $(M=5.19)$ at follow-up. The ANCOVA for sun exposure revealed no significant group differences (see Table 2).

Stage of change data were examined using chi-square analyses with dependent variables identified as (a) the proportion of participants in each group advancing at least one stage across time and (b) the proportion of participants in each group regressing at least one stage across time. Results revealed that $25 \%$ of control group and $49 \%$ of intervention group participants advanced in stage, $\chi^{2}(2, N=100)=5.742, p<.02$ (two-tailed) and that there was no difference between the intervention (12\%) and control group participants $(15 \%)$ in stage regression.

\section{Discussion}

In the present study we examined the efficacy of a multicomponent intervention that targeted sun protection motivation and behavior in a setting where high-risk behavior is most prevalent, that is, the beach. Results revealed that the intervention significantly impacted sun protection motivation and behavior, but not sun exposure.

Results were consistent with those of other multicomponent interventions that have aimed to increase the saliency of the deleterious effects of unprotected sun exposure (Brandberg et al., 1996; Robinson \& Rademaker, 1995; Weinstock et al., 1998). Whether the increased saliency of personal risk drives increased sun protection behavior and motivation or has an additive effect is not clear; however, the extent to which an individual perceives a personal risk for skin cancer appears to be important. The results also support the importance of addressing motivation to change. Although behavior changes were observed, observed changes in motivation were more substantial and provide additional information about the impact of the intervention. Few skin cancer prevention studies have assessed intervention impact on motivational stages, a measure that may be more sensitive to the process of change than behavior change measures alone (Rossi et al., 1995).

After controlling for covariates, we found that sun exposure ratings at follow-up did not appear to be affected by the intervention. Sun exposure among intervention participants did, however, show a decreasing trend from baseline to follow-up. This trend may have resulted from intervention exposure or, possibly, regression to the mean, that is, intervention participants reported significantly greater sun exposure than control participants at baseline.

The lack of significant change in sun exposure behavior is consistent with prior research, which rarely indicates that sun exposure is reduced when sun protection behavior increases (Autier et al., 1999; Wright, Wright, \& Wagner, 2001). Plausibly, the motivating factors for sun protection behavior differ from those for sun exposure, or more likely, individuals might perceive the use of sun protection as an adequate measure in the reduction of suninduced risks. As such, sunbathers who use sunscreen could perceive themselves as safe from the risks of sun exposure and continue prolonged sun exposure patterns. Health promotion efforts are needed to examine interventions that foster the belief that reduced sun exposure is a necessary step in reducing skin cancer risk.

Table 2

Comparison of Group Means on Dependent Variables at Baseline and 2-Month Follow-Up

\begin{tabular}{|c|c|c|c|c|c|c|c|c|c|c|}
\hline \multirow[b]{3}{*}{ Variable } & \multicolumn{5}{|c|}{ Intervention } & \multicolumn{5}{|c|}{ Control } \\
\hline & \multirow[b]{2}{*}{$n$} & \multicolumn{2}{|c|}{ Baseline } & \multicolumn{2}{|c|}{ Follow-up } & \multirow[b]{2}{*}{$n$} & \multicolumn{2}{|c|}{ Baseline } & \multicolumn{2}{|c|}{ Follow-up } \\
\hline & & $M$ & $S D$ & $M$ & $S D$ & & $M$ & $S D$ & $M$ & $S D$ \\
\hline Sun protection & 53 & 5.52 & 1.84 & 6.44 & 1.80 & 47 & 5.55 & 1.85 & 5.19 & $1.84^{*}$ \\
\hline Sun exposure & 53 & 14.90 & 16.90 & 8.96 & 9.00 & 47 & 7.53 & 7.01 & 6.85 & 5.09 \\
\hline
\end{tabular}


A few limitations of this study should be given consideration. The rate of failure to follow up was high, possibly because of the transient nature of beachgoers and the relatively small incentive for completing and returning follow-up questionnaires (i.e., the $\$ 100$ lottery). Threats to generalizability were reduced because no significant differences in demographic or study variables were observed between completers and noncompleters. Also, the use of nonrandomized groups may have accounted for baseline group differences in recreational sun exposure, age, gender, and possibly other unknown characteristics. To reduce sampling bias, we statistically controlled for observed group differences in the analyses. Another potential limitation concerns the relatively small 2-month follow-up period. Extended follow-up assessments (e.g., 1 year) would have allowed for evaluation of the long-term effects of the intervention. The relatively low internal consistency of the measures of sun protection and exposure is an additional limitation. The skin cancer literature lacks standardized measures of sun protection and exposure; however, attempts were made to adapt measures used in previous studies (Pratt \& Borland, 1994; Wichstrøm, 1994) to the purposes of the present study. Finally, the average score of sun protection behavior increased in the intervention group by only 0.81 in a possible score range of $1-7$. Although this is a small behavioral change, the stage of change outcome suggests that the intervention was robust enough to push $50 \%$ of the intervention participants forward in their sun protection motivation. A progression of even just one stage is meaningful because the individual is closer to making and maintaining changes. Stage progression was associated with some, albeit modest, behavioral changes.

In summary, health promotion efforts should continue to develop interventions that facilitate both motivational and behavioral changes. Our study supports the use of a "one-shot" intervention that provides education while increasing the saliency of risks associated with unprotected sun exposure. Larger and more sustained changes might result from a prolonged version of the intervention that allows for multiple exposures. Research is still needed to differentiate the importance of sun avoidance from sun protection. Interventions that facilitate sun protection may not be effective at facilitating sun avoidance. Future research should explore variables that concomitantly reduce sun exposure and increase sun protection behaviors.

\section{References}

American Cancer Society. (1999). It's your skin. Wear it well [Brochure]. Atlanta: Author.

Autier, P., Dore, J. F., Negrier, S., Lienard, D., Panizzon, R., Lejeune, F. J., et al. (1999). Sunscreen use and duration of sun exposure: A doubleblind, randomized trial. Journal of the National Cancer Institute, 91, 1304-1309.

Balanda, K., Stanton, W. R., Lowe, J. B., \& Purdue, J. (1999). Predictors of sun protective behaviors among school students. Behavioral Medicine, 25, 28-35.

Brandberg, Y., Bolund, C., Michelson, H., Mansson-Brahme, E., Ringborg, U., \& Sjoden, P. O. (1996). Perceived susceptibility to and knowledge of malignant melanoma: Screening participants vs the general population. Preventive Medicine, 25, 170-177.

Broadstock, M., Borland, R., \& Hill, D. (1996). Knowledge, attitudes and reported behaviours relevant to sun protection and suntanning in adolescents. Psychology \& Health, 11, 527-539.

Center for Disease Control. (1995). Deaths from melanoma: United States, 1973-1992. Morbidity and Mortality Weekly Reports, 44, 343-347.

Detweiler, J. B., Bedell, B. T., Salovey, P., Pronin, E., \& Rothman, A. J. (1999). Message framing and sunscreen use: Gain-framed messages motivate beachgoers. Health Psychology, 18, 189-196.

Dixon, H., Borland, R., \& Hill, D. (1999). Sun protection and sunburn in primary school children: The influence of age, gender, and coloring. Preventive Medicine, 28, 119-130.

Hillhouse, J. J., \& Turrisi, R. (2002). Examination of the efficacy of an appearance-focused intervention to reduce UV exposure. Journal of Behavioral Medicine, 25, 395-409.

Jackson, K. M., \& Aiken, L. S. (2000). A psychosocial model of sun protection and sunbathing in young women: The impact of health beliefs, attitudes, norms, and self-efficacy for sun protection. Health Psychology, 19, 469-478.

Jones, F., Harris, P., \& Chrispin, C. (2000). Catching the sun: An investigation of sun-exposure and skin protective behaviour. Psychology Health \& Medicine, 5, 131-141.

Katz, R. C., \& Jernigan, S. (1991). Brief report: An empirically derived educational program for detecting and preventing skin cancer. Journal of Behavioral Medicine, 14, 421-428.

Koh, H. K., Geller, A. C., Miller, D. R., Grossbart, T. A., \& Lew, R. A. (1996). Prevention and early detection strategies for melanoma and skin cancer. Archives of Dermatology, 132, 436-443.

Koh, H. K., Geller, A. C., Miller, D. R., \& Lew, R. A. (1995). The early detection and screening for melanoma: International status. Cancer, 75, 674-693.

Lombard, D., Neubauer, T. E., Canfield, D., \& Winett, R. A. (1991) Behavioral community intervention to reduce the risk of skin cancer. Journal of Applied Behavior Analysis, 24, 677-686.

Lowe, J. B., Borland, R., Stanton, W. R., Baade, P., White, V., \& Balanda, K. P. (2000). Sun-safe behaviour among secondary school students in Australia. Health Education Research, 15, 271-281.

Miller, D. L., \& Weinstock, M. A. (1994). Nonmelanoma skin cancer in the United States: Incidence. Journal of the American Academy of Dermatology, 30, 774-778.

Miller, D. R., Geller, A. C., Wood, M. C., Lew, R. A., \& Koh, H. K. (1999). The Falmouth Safe Skin Project: Evaluation of a community program to promote sun protection in youth. Health Education \& Behavior, 26, 369-384.

Newman, W. G., Agro, A. D., Woodruff, S. L., \& Mayer, J. A. (1996). A survey of recreational sun exposure of residents of San Diego, California. American Journal of Preventive Medicine, 12, 186-194.

Nicol, N. H., \& Fenske, N. A. (1993). Photodamage: Cause, clinical manifestations, and prevention. Dermatology Nursing, 5, 276-277.

Pratt, K., \& Borland, R. (1994). Predictors of sun protection among adolescents at the beach. Australian Psychologist, 29, 135-139.

Prochaska, J. O., \& DiClemente, C. C. (1983). Stages and processes of self-change of smoking: Toward an integrative model of change. Journal of Consulting and Clinical Psychology, 51, 390-395.

Prochaska, J. O., Velicer, W. F., Rossi, J. S., Goldstein, M. G., Marcus, B. H., Rakowski, W., et al. (1994). Stages of change and decisional balance for 12 problem behaviors. Health Psychology, 13, 39-46.

Robinson, J. K., \& Rademaker, A. W. (1995). Skin cancer risk and sun protection learning by helpers of patients with nonmelanoma skin cancer. Preventive Medicine, 24, 333-341.

Rossi, J. S., Blais, L. M., Redding, C. A., \& Weinstock, M. A. (1995). Preventing skin cancer through behavior change: Implications for intervention. Dermatoepidemiology, 13, 613-622.

Rossi, J. S., Blais, L. M., \& Weinstock, M. A. (1994). The Rhode Island 
Sun Smart Project: Skin cancer prevention reaches the beaches. American Journal of Public Health, 84, 672-674.

Rothman, A. J., Salovey, P., Antone, C., Keough, K., \& Martin, D. (1993). The influence of message framing on intentions to perform health behaviors. Journal of Experimental Social Psychology, 29, 408-433.

Weinstock, M. A. (1992). Assessment of sun sensitivity by questionnaire: Validity of items and formulation of a prediction rule. Journal of Clinical Epidemiology, 45, 547-552.

Weinstock, M. A., \& Rossi, J. S. (1998). The Rhode Island Sun Smart Project: A scientific approach to skin cancer prevention. Clinics in Dermatology, 16, 411-413.

Weinstock, M. A., Rossi, J. S., Redding, C. A., \& Maddock, J. E. (1998).
Randomized trial of intervention for sun protection among beachgoers [Abstract]. Journal of Investigational Dermatology, 110, 569.

Weinstock, M. A., Rossi, J. S., Redding, C. A., Maddock, J. E., \& Cottrill, S. D. (2000). Sun protection behaviors and stages of change for the primary prevention of skin cancers among beachgoers in Southeastern New England. Annals of Behavioral Medicine, 22, 286-293.

Wichstrøm, L. (1994). Predictors of Norwegian adolescents' sunbathing and use of sunscreen. Health Psychology, 13, 412-420.

Wright, M. W., Wright, S. T., \& Wagner, R. F. (2001). Mechanisms of sunscreen failure. Journal of the American Academy of Dermatology, 44, 781-784.

\title{
Call for Nominations
}

The Publications and Communications ( $\mathrm{P} \& \mathrm{C}$ ) Board has opened nominations for the editorships of Comparative Psychology, Experimental and Clinical Psychopharmacology, Journal of Abnormal Psychology, Journal of Counseling Psychology, and.JEP: Human Perception and Performance for the years 2006-2011. Meredith J. West, PhD, Warren K. Bickel, PhD, Timothy B. Baker, PhD, JoIda C. Hansen, $\mathrm{PhD}$, and David A. Rosenbaum, $\mathrm{PhD}$, respectively, are the incumbent editors.

Candidates should be members of APA and should be available to start receiving manuscripts in early 2005 to prepare for issues published in 2006. Please note that the P\&C Board encourages participation by members of underrepresented groups in the publication process and would particularly welcome such nominees. Self-nominations also are encouraged.

Search chairs have been appointed as follows:

- Comparative Psychology, Joseph J. Campos, PhD

- Experimental and Clinical Psychopharmacology, Linda P. Spear, PhD

- Journal of Abnormal Psychology, Mark Appelbaum, PhD, and David C. Funder, $\mathrm{PhD}$

- Journal of Counseling Psychology, Susan H. McDaniel, PhD, and William C. Howell, PhD

- JEP: Human Perception and Performance, Randi C. Martin, PhD

To nominate candidates, prepare a statement of one page or less in support of each candidate. Address all nominations to the appropriate search committee at the following address:

\author{
Karen Sellman, P\&C Board Search Liaison \\ Room 2004 \\ American Psychological Association \\ 750 First Street, NE \\ Washington, DC 20002-4242
}

The first review of nominations will begin December 8, 2003. The deadline for accepting nominations is December 15, 2003. 